Article

\title{
Rye and Oat Agricultural Wastes as Substrate Candidates for Biomass Production of the Non-Conventional Yeast Yarrowia lipolytica
}

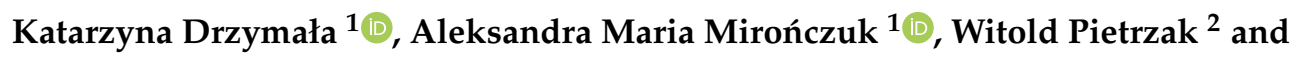 \\ Adam Dobrowolski 1,*(D) \\ 1 Department of Biotechnology and Food Microbiology, Wrocław University of Environmental and \\ Life Sciences, 50-375 Wrocław, Poland; katarzyna.drzymala@upwr.edu.pl (K.D.); \\ aleksandra.mironczuk@upwr.edu.pl (A.M.M.) \\ 2 Department of Fermentation and Cereals Technology, Wrocław University of Environmental and \\ Life Sciences, 50-375 Wrocław, Poland; witold.pietrzak@upwr.edu.pl \\ * Correspondence: adam.dobrowolski@upwr.edu.pl
}

Received: 4 August 2020; Accepted: 10 September 2020; Published: 18 September 2020

\begin{abstract}
The aim of this study was to test rye straw, rye bran and oat bran hydrolysates as substrates for growth of the yeast Yarrowia lipolytica, a microorganism known to have large biotechnological potential. First, after the combined process of acid-enzymatic hydrolysis, the concentration and composition of fermentable monosaccharides in the obtained hydrolysates were analyzed. Glucose was the main sugar, followed by xylose and arabinose. Rye bran hydrolysate had the highest sugar content- $80.8 \mathrm{~g} / \mathrm{L}$. The results showed that this yeast was able to grow on low-cost medium and produce biomass that could be used as a feed in the form of single cell protein. The biomass of yeast grown in oat bran hydrolysate was over $9 \mathrm{~g} / \mathrm{L}$ after $120 \mathrm{~h}$, with the biomass total yield and total productivity values of $0.141 \mathrm{~g} / \mathrm{g}$ and $0.078 \mathrm{~g} / \mathrm{h}$, respectively. The protein contents in yeast biomass were in the range of $30.5-44.5 \%$ of dry weight. Results obtained from Y. lipolytica cultivated in rye bran showed high content of exogenous amino acid (leucine $3.38 \mathrm{~g}$, lysine $2.93 \mathrm{~g}$, threonine $2.31 \mathrm{~g} / 100 \mathrm{~g}$ of dry mass) and spectrum of unsaturated fatty acid with predominantly oleic acid-59.28\%. In conclusion, these results demonstrate that lignocellulosic agricultural waste, after hydrolysis, could be efficiently converted to feed-related yeast biomass.
\end{abstract}

Keywords: Yarrowia lipolytica; biomass production; agricultural wastes

\section{Introduction}

According to the latest estimates by the Food and Agriculture Organization, global production levels of rye and oat in 2018 were $11.27 \times 10^{6}$ and $23.05 \times 10^{6}$ tons, respectively. However, utilization of agricultural wastes is infrequent. It can be assumed that they represent a notable proportion of waste matter in industrialized countries. During food production, straw and bran are generated as waste products and only part of these are utilized in other industries. Plant biomass constitutes a huge reservoir of organic carbon that still is not used on a large scale. Nowadays, many efforts are made to apply plant biomass as a substrate for biotechnological processes. Some microorganisms such as Trichoderma sp. produce cellulases, and thus are able to degrade the plant cell wall [1]. However, many microorganisms that are applied in biotechnology do not have this capability. The next disadvantage of this feedstock is the presence of furfural and 5-hydroxymethylfurfural (5-HMF) that are formed during acidic and thermal dehydration of sugars, and are highly toxic for some microorganisms [2]. In the non-detoxified wheat straw hydrolysates, furfural and HMF were detected at concentration 
$0.5 \mathrm{~g} / \mathrm{L}$ [3]. Results indicate that both biomass of microorganisms and lipid content could drop when furfural or HMF is present in hydrolysates used as a growth broth.

For this reason, still, pure sugars, especially glucose, are the fundamental substrates used by the biotechnological industry. The utilization of renewable lignocellulosic biomass as a feedstock for microbial bioprocess is an interesting option to increase the economic profitability of the biotechnological production and sustainability of applied processes. The primary stock of lignocellulose originates from plant secondary cell walls, the thick layer formed inside the cell after it is fully grown. Approximately $75 \%$ of lignocellulose can potentially be converted into monosaccharides [4]. Plant biomass contains mainly glucose, xylose, galactose, arabinose and mannose [5]. Some previous research has shown that hydrolyzed agricultural residues can be successfully used as a fermentation medium for yeast. Lipomyces starkeyi and Rhodotorula babjevae were tested for growth in wheat straw hydrolysate and the dry matter of both strains increased to $11 \mathrm{~g} / \mathrm{L} \mathrm{[6].} \mathrm{Lignocellulosic} \mathrm{hydrolysates} \mathrm{derived} \mathrm{from}$ corn stover was used for lipid production by Rhodosporidium toruloides [7]. Genetically engineered Saccharomyces cerevisiae was used for fermentations on different liquor wheat straw hydrolysates [8]. Conversion of agave residues into liquid biofuels was a subject of research as well [9]. Moreover, Y. lipolytica yeast grown in rice bran hydrolysate [10] or sugarcane bagasse hydrolysate was used for fermentation [11]. Yeast Y. lipolytica was also cultivated on agricultural wastes and produced single cell oil (SCO) from these substrates $[12,13]$. Lignocellulosic wastes possess considerable potential to be an alternative low-cost and environmentally friendlier feedstock to produce high-added-value products.

Y. lipolytica is one of the most extensively studied "non-Saccharomyces" yeasts due to its metabolic characteristics and prospective applications. It is considered as being generally recognized as safe (GRAS) by the U.S. Food and Drug Administration (FDA, USA), which is crucial when microorganisms are intended to be used in feed or food applications. Currently, the yeast $Y$. lipolytica is used in the synthesis of organic acids [14,15], in the synthesis of sweeteners [16], fatty acids [17,18], enzymes [19] and biomass [20]. Y. lipolytica is also used for production of single-cell protein [21]. Moreover, the European Feed Manufacturers' Federation authorized the usage of Y. lipolytica fodder yeast (catalog number 00 575-EN) [22]. Nowadays, soybean meal is a crucial protein source used in livestock production, but the inclusion of microbial biomass as a replacement in animal diets up to $100 \%$ is suggested [23]. The protein and fat content of Y. lipolytica A101 biomass has been indicated as over $20 \%$ and $14 \%$, respectively [22]. Biomass of yeast is characterized by a wide amino acid profile and high protein-carbohydrate ratio, and it is particularly attractive and suitable for the food and feed industries - the contents of some exogenous amino acids in the biomass were higher than those observed in proteins from eggs [24]. Yeast is also a source of macroelements such as sodium or calcium and micronutrients such as zinc or selenium [25]. Some studies indicate that certain yeast species have the potential to reduce the transmission of prions-misfolded proteins that can cause neurodegeneration, and whose transmission occurs in livestock farms [26]. Furthermore, microbial products can be independent of farmland, water and changing climatic conditions.

The aim of this study was to investigate the possibility of using rye straw, rye bran and oat bran hydrolysate as a carbon source for Y. lipolytica A101, a wild-type strain, for biomass production. As far as we know, this is the first report about applying these types of substrates for Y. lipolytica.

\section{Materials and Methods}

\subsection{Microorganisms}

The strain used in this study was Y. lipolytica A101, isolated from polluted soil at a car wash [27,28]. The isolate is part of the strain collection belonging to the Department of Biotechnology and Food Microbiology at Wrocław University of Environmental and Life Sciences, Poland. 


\subsection{Preparation of Hydrolysates from Agricultural Wastes}

Rye straw, rye bran and oat bran were obtained from a commercial mill. The raw materials were subjected to hydrolysis. Biomasses were ground to powder by a hand grinder and hydrolyzed. At the first step, materials were diluted with $1 \%$ sulfuric acid (in the ratio $10 \% \mathrm{~m} / \mathrm{v}$ ) and left for an hour under a pressure of $106 \mathrm{kPa}(1 \mathrm{~atm})$ and temperature of $121^{\circ} \mathrm{C}$. Subsequently, the acid was neutralized with $20 \% \mathrm{NaOH}$ to $\mathrm{pH}=5.0$ and after re-sterilization under standard conditions, an enzyme blend of cellulases, $\beta$-glucosidases and hemicellulases (Sigma-Aldrich, Munich, Germany, cat. no.: SAE0020) was added in excess of $2 \%$ volume. Hydrolysis processes were carried out in an incubator shaker for $72 \mathrm{~h}\left(50^{\circ} \mathrm{C}\right.$ at $\left.180 \mathrm{rpm}\right)$. The products were then centrifuged and the supernatant was sterilized by membrane filtration (Stericup Filter Units, $0.22 \mu \mathrm{m}$ Durapore, Merck Millipore). The obtained hydrolysates were kept in refrigerated conditions between the experiments.

\subsection{Spot Test}

The potential for hydrolysates to be used as a carbon source by yeast was initially verified by spot test. $20 \mathrm{~mL}$ of hydrolysate enriched with a nitrogen source (6.7 g/L Yeast Nitrogen Base, Sigma-Aldrich) was combined with liquefied agar $(2 \%)$ and poured into a plastic petri dish. Droplets $(2 \mu \mathrm{L})$ of serial dilutions of yeast inoculum $(\mathrm{OD} 600=1)$ were spotted on the surface of agar and then were incubated at $28^{\circ} \mathrm{C}$ for $48 \mathrm{~h}$.

\subsection{Growth of Y. lipolytica in Bioscreen C}

YNB medium supplemented with glucose $20 \mathrm{~g} / \mathrm{L}$ (Merck, Germany) was used for the yeast inoculum preparation. The inoculation cultures were grown for $24 \mathrm{~h}$ in $0.1 \mathrm{~L}$ flask; afterwards, the overnight cultures were spun down and washed with sterile water. The yeast strain was grown in 100-well plates in $250 \mu \mathrm{L}$ of hydrolysate supplemented with $6.7 \mathrm{~g} / \mathrm{L}$ Yeast Nitrogen Base (Sigma-Aldrich) and in $250 \mu \mathrm{L}$ of YNB medium with $2 \%$ of glucose as a control sample. Inoculation culture were transferred in a volume of $5 \mu \mathrm{L}$ to each well to an OD600 of 0.1. Experiments were performed in quintuplicate at $28{ }^{\circ} \mathrm{C}$ under constant agitation with Bioscreen C (Oy Growth Curves Ab Ltd.). Growth was monitored measuring optical density at 420-600 $\mathrm{nm}$ every $30 \mathrm{~min}$ during $48 \mathrm{~h}$.

\subsection{Shake-Flask Experiments}

The growth medium used for the inoculum was the same as for Bioscreen $C$ analysis. The biomass production medium for the shake-flask experiment consisted of $50 \mathrm{~mL}$ of hydrolysate supplemented with $6.7 \mathrm{~g} / \mathrm{L}$ Yeast Nitrogen Base (Sigma-Aldrich). The cultures were grown in a $0.25 \mathrm{~L}$ flask on a rotary shaker under constant conditions of $28^{\circ} \mathrm{C}$ at shaking $180 \mathrm{rpm}$ for $120 \mathrm{~h}$. All cultures were conducted in three biological replicates.

\subsection{Analytical Methods}

(I) The concentrations of glucose, xylose, galactose, arabinose and mannose in obtained hydrolysates were determined by HPLC using a Carbohydrate Analysis Column Aminex HPX-87P (Bio-Rad, Irvine, CA, USA) coupled to a UV (Dionex, Sunnyvale, CA, USA) and a refractive index (RI) detector (Shodex, Tokyo, Japan). The column was eluted with sterile water at $65^{\circ} \mathrm{C}$ and a flow rate of $0.6 \mathrm{~mL} / \mathrm{min}$. Sugars were identified and quantified by the comparison to standards material.

(II) $10 \mathrm{~mL}$ of samples from the shake-flask cultures were centrifuged ( $5 \mathrm{~min} ; 5500 \times \mathrm{g}$ ), harvested by filtration on $0.45 \mu \mathrm{m}$ membranes-the biomass was determined gravimetrically after drying at $105^{\circ} \mathrm{C}$.

(III) The amino acid profile was examined by the Amino Acid Analytic Laboratory in the Department of Animal Nutrition and Feed Management (University of Environmental and Life Sciences, Wrocław, Poland). The determination of the crude protein was carried out by the method AOAC 984.13 on FOSS Tecator Digestor 2508 and FOSS 2300 Kjeltec Analyzer Unit. Sulfur amino acids were oxidized with a mixture of $30 \%$ hydrogen peroxide and formic acid, hydrolyzed with $6 \mathrm{M}$ 
hydrochloric acid and analyzed on AAA-400 instrument (INGOS, Czech Republic). Tryptophan was determined spectrophotometrically (HALO DB-20 UV-vis Double beam Spectrophotometer, Dynamica, United Kingdom). Other amino acids were hydrolyzed with $6 \mathrm{M}$ hydrochloric acid and analyzed on AAA-400 instrument (INGOS, Czech Republic).

(IV) The lipid profile was examined by converting lipids into their methyl esters $[17,29]$. Fatty acids were identified and quantified with a Zebron ZB-FAME column installed in the Shimadzu single quadrupole GCMS-QP2010SE system with hexane as a solvent and helium as a carrier gas (linear velocity- $35 \mathrm{~cm} / \mathrm{s}$ ). As a reference material, 37 FAME MIX (CRM47885, Sigma-Aldrich) was used.

\subsection{Calculation of Fermentation Parameters}

The biomass total yield was calculated using the formula: $Y_{c}=X / S . X$ is the total amount of biomass at the end of the experiment, $\mathrm{S}$ is the amount of total sugars in the hydrolysate and is expressed in $\mathrm{g} / \mathrm{g}$. The biomass total productivity $(\mathrm{Qx})$ was calculated by: $\mathrm{Qx}=\mathrm{X} / 120$ and is expressed in $\mathrm{g} / \mathrm{L} \times \mathrm{h}$.

\section{Results and Discussion}

\subsection{Acid-Enzymatic Hydrolysis of Raw Material}

In this study, hydrolysates were prepared using a combined methodology of acid and enzymatic hydrolysis. Acid pretreatment with sulfuric acid, performed under increased pressure and high temperature, allows for decomposition of hemicellulose and dissolution of lignin. Nonetheless, it could present risks of release of toxic compounds, such as furfural or acetic acid [30]. Enzymatic hydrolysis was performed with an enzyme blend of cellulases, $B$-glucosidases and hemicellulases. The results showed that the final concentration of total fermentable sugars was $28.1 \mathrm{~g} / \mathrm{L}$ for rye straw hydrolysate, $80.8 \mathrm{~g} / \mathrm{L}$ for rye bran hydrolysate and $66.2 \mathrm{~g} / \mathrm{L}$ for oat bran; the percentage of sugars in hydrolysates is shown in Table 1.

Table 1. Sugar composition of each tested hydrolyzed agricultural residues. The hydrolysates were obtained by acid and enzymatic hydrolysis. The concentrations of glucose, xylose, galactose, arabinose and mannose in obtained hydrolysates were determined with HPLC.

\begin{tabular}{ccccc}
\hline & & Rye Straw & Rye Bran & Oat Bran \\
\hline & $\Sigma$ sugar & 28.1 & 80.8 & 66.2 \\
& glucose & 7.79 & 67.06 & 62.74 \\
{$[\mathrm{~g} / \mathrm{L}]$} & xylose & 17.19 & 7.56 & 1.23 \\
& galactose & 0.42 & 0.44 & 0.47 \\
& arabinose & 2.44 & 3.55 & 1.15 \\
& mannose & 0.26 & 2.19 & 0.61 \\
\hline
\end{tabular}

Typically, lignocellulosic hydrolysate (sourced from various types of straws or hardwood) usually consists of up to $63 \%$ glucose and $36 \%$ xylose [31]. The majority of the carbohydrate in cereal is starch-polysaccharide comprising glucose monomers. Oat bran hydrolysate was almost exclusively composed of this monosaccharide. Rye bran hydrolysate, in addition to glucose, also contains significant amounts of xylose (less than 10\%) and less than $5 \%$ of arabinose. What is important to note, is that the yeast $Y$. lipolytica can utilize both of these sugars, although pentose metabolism is poorly understood [32] and the xylose utilization pathway has to be induced [33]. Similar to wood, straw mainly consists of hemicelluloses-the main sugar found in this fraction is xylose [34]. Consequently, rye straw hydrolysate contained the most diverse sugar composition-over $61 \%$ xylose, $27.74 \%$ glucose and nearly $9 \%$ arabinose. Even though the wild strain of $Y$. lipolytica is unable to effectively utilize xylose as a primary carbon source [35], glucose and xylose were found to be assimilated from the medium simultaneously. However, arabinose was catabolized only after all available glucose had been consumed [11]. Hydrolysates, after removal of plant residues and the sterilization process, consisted of a translucent brown-colored solution. From the initial volume of $2 \mathrm{~L}$, it was possible to obtain about 
$75 \%$ of pure hydrolysate. Taking into account the composition of the hydrolysates, we started the first growth experiments.

\subsection{Growth of Y. lipolytica A101 on Hydrolysates}

Prepared hydrolysates were rich in carbohydrates and could be regarded as a potential nutrient source for yeast biomass production. First, to ensure that hydrolysates do not contain excessive amounts of compounds potentially inhibiting yeast growth, YNB media containing various types of hydrolysates were tested, and as a control, a medium with pure glucose was used. To test the growth of Y. lipolytica, a microplate reader was used. As seen in Figure 1, Y. lipolytica was able to grow in all media, both in various raw material-based media and the pure glucose control.

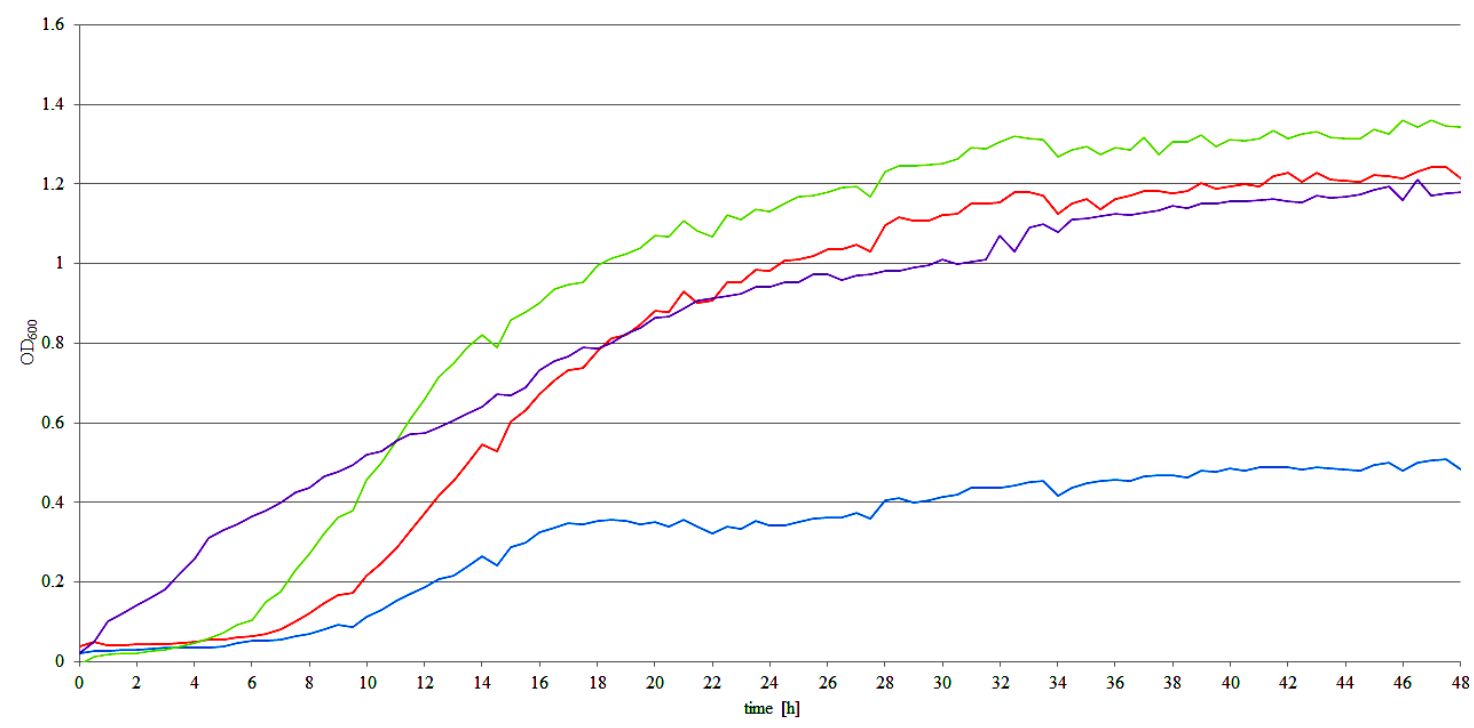

Figure 1. Growth of Y. lipolytica A101 on YNB medium based on obtained hydrolysates-oat bran (green line), rye bran (red line), rye straw (blue line), and YNB medium supplemented with 2\% of glucose-control (violet line) during the $48 \mathrm{~h}$ of fermentation.

Comparing the growth of yeast on hydrolysates with growth on medium containing $20 \mathrm{~g} / \mathrm{L}$ pure glucose, we noted a slightly longer lag phase. However, this slow delay of growth did not have any significant influence of the final optimal density of the $Y$. lipolytica. The yeast achieved the highest OD600 value after $24 \mathrm{~h}$ in the case of a medium with oat bran hydrolysate. Rye bran hydrolysate allowed yeast to grow to a similar OD600 as the control. An exception was growth on rye straw hydrolysate where a noticeably lower OD600 value was observed. Probably a lower concentration of easily accessible glucose and high concentration of nonpreferred xylose and, presumably, the high quantities of furfural impurities from hemicelluloses might have a negative effect on yeast growth. Figure 1 shows that all types of tested plant-based hydrolysates are efficiently utilized by Y. lipolytica and can be used as a substrate. Subsequently, to test the growth of yeast of the solid-state fermentation, spot tests with hydrolysates-based medium supplemented with a nitrogen source and agar were performed. For the spot test experiment, the exponentially growing cells were also spotted onto plates and incubated for $48 \mathrm{~h}$ at $28^{\circ} \mathrm{C}$. As seen in Figure 2, after this period, a fast growth on all hydrolysates has been observed. The growth on oat bran and rye bran was slightly better than on rye straw, which is in line with results obtained in the microplate reader growth experiment. Similar to results obtained from the microplate reader, the growth on rye straw was slightly slower, probably, as mentioned above, due to low glucose and high xylose concentration. Moreover, in this experiment, a toxic influence of inhibitors was almost unnoticeable. 


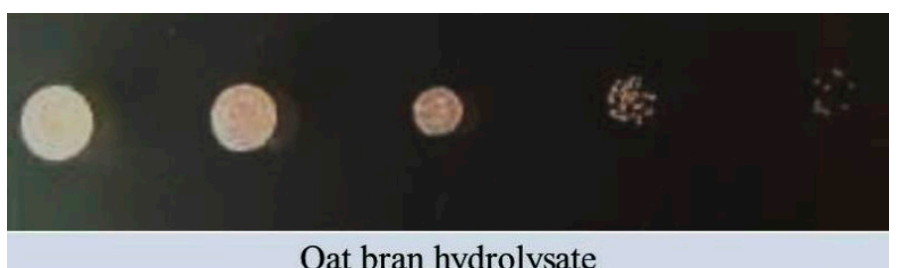

Oat bran hydrolysate

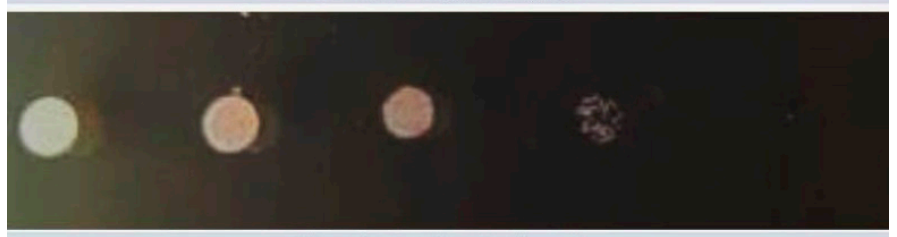

Rye bran hydrolysate

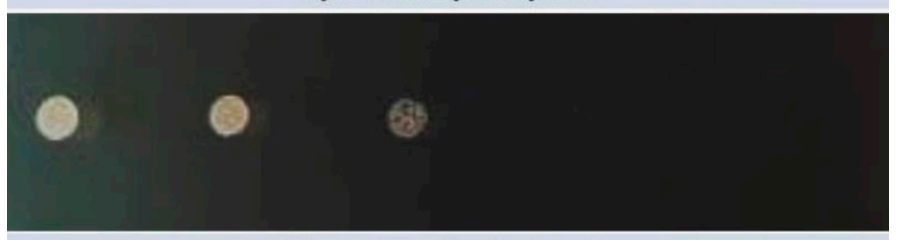

Rye straw hydrolysate

Figure 2. Growth of Y. lipolytica A101 after $48 \mathrm{~h}$ on agar medium composed from hydrolysates supplemented with a nitrogen source.

\subsection{Shake-Flask Experiments with Agricultural Waste Medium}

The next step in the study was growth of Y. lipolytica in the shake-flask experiment with hydrolysates as a substrate. Each hydrolysate was supplemented with yeast nitrogen base containing $5 \mathrm{~g} / \mathrm{L}$ ammonium sulfate. In contrast to the previous experiment, $Y$. lipolytica was grown in a larger volume, and oxygen supply in the medium was better. Previously, it was shown that providing a high level of dissolved oxygen is crucial for efficient growth of Y. lipolytica [36]. The fermentation process took $120 \mathrm{~h}$, and the obtained results of biomass production are shown in Figure 3 and Table 2.

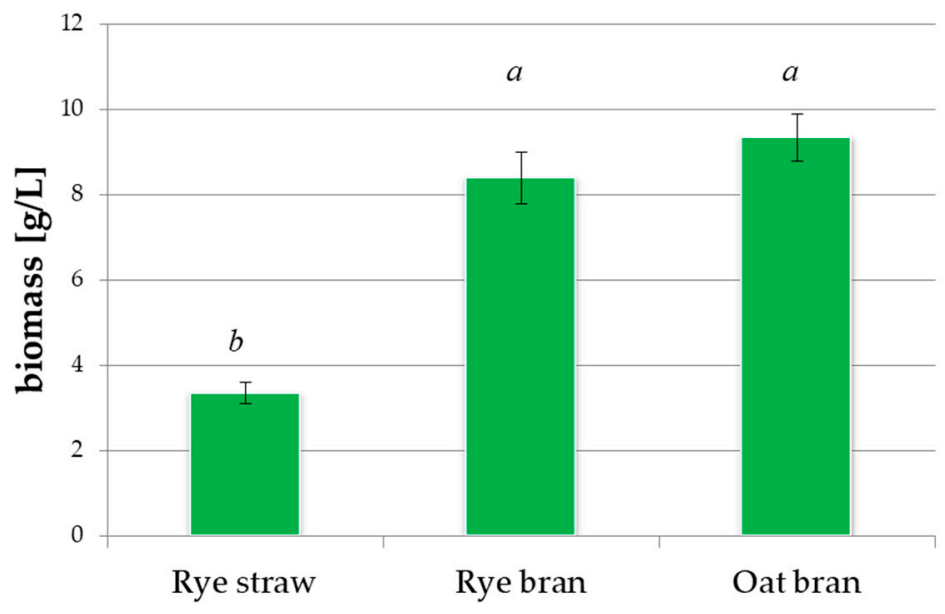

Figure 3. Parameters of biomass production by Y. lipolytica A101 grown on hydrolysates-based medium supplemented by YNB. The results were statistically analyzed with the Statistica 13.3 software package (TIBCO Software Inc.). One-way ANOVA at $p \leq 0.05$ was calculated and homogeneous groups according to the Duncan test were estimated. Mean values over the bars that are not significantly different from each other $(p>0.05)$ are represented by the same letter. 
Table 2. The biomass total yield and productivity.

\begin{tabular}{cccc}
\hline \multirow{2}{*}{ Hydrolysates } & Biomass & $\mathbf{Y}_{\mathbf{c x} / \mathbf{s}}$ & $\mathbf{Q}_{\mathbf{x}}$ \\
\cline { 2 - 4 } & {$[\mathrm{g} / \mathrm{L}]$} & {$[\mathrm{g} / \mathrm{g}]$} & {$[\mathrm{g} / \mathrm{L} \cdot \mathbf{h}]$} \\
\hline Rye straw & $3.35 \pm 0.25$ & $0.119 \pm 0.009$ & $0.028 \pm 0.002$ \\
Rye bran & $8.40 \pm 0.60$ & $0.104 \pm 0.007$ & $0.070 \pm 0.005$ \\
Oat bran & $9.35 \pm 0.55$ & $0.141 \pm 0.008$ & $0.078 \pm 0.005$ \\
\cline { 2 - 4 } $\mathrm{Y}_{\mathrm{c} \times / \mathrm{s}}$ - the biomass total yield; $\mathrm{Q}_{\mathrm{x}}$ 一the biomass total productivity. Values are means $\pm \mathrm{SD}$ of three determinations.
\end{tabular}

As seen, the yeast grown in oat bran hydrolysate achieved the highest biomass level of $-9.35 \mathrm{~g} / \mathrm{L}$. By contrast, for rye straw hydrolysate, the biomass reached only $3.35 \mathrm{~g} / \mathrm{L}$. This result confirmed the Bioscreen $C$ experiment, where a higher cell density was noted for oat bran and a lower value for straw. Surprisingly, oat bran hydrolysate was the best substrate for production of biomass, despite having a lower total sugar content than rye bran. However, other studies have also shown the non-obvious dependence of biomass increase on the amount of sugars in the medium. The maximum biomass of Trichosporon fermentans was attained at $15 \%$ sugar concentration, and an increase of up to $30 \%$ did not bring a further increase in biomass [37]. The same trend was observed for Y. lipolytica-increased sugar content from $30 \mathrm{~g} / \mathrm{L}$ to $40 \mathrm{~g} / \mathrm{L}$ resulted in lowering of cell growth [10]. Too high concentration of sugar can cause higher osmotic stress, then, instead of biomass erythritol produced, to protect the cell against unfavorable conditions [16]. In this study, the biomass total yield $\left(\mathrm{Y}_{\mathrm{c}}\right)$ and the biomass total productivity $\left(Q_{x}\right)$ had the highest values for oat bran-based medium $-0.141 \mathrm{~g} / \mathrm{g}$ and $0.078 \mathrm{~g} / \mathrm{h}$, respectively. It clearly shows that $Y$. lipolytica is able to convert agricultural wastes for growth and biomass production, as well as other waste substrates from other industries [12,13]. This is a good starting point for further optimization of the process. Biomass of $Y$. lipolytica can be used not only as a fodder, but potentially eventually as a host for production of other value-added products such as lipids or organic acids. The process optimization might include not only medium or fermentation conditions' optimization, but mainly metabolic engineering of the yeast that helps to achieve better utilization of the natural potential of this microorganism for growth on untypical substrates, despite the toxic impurities. However, it is important to note that, in the context of food applications, attention should be paid to the use of non-genetically modified microorganisms. The employment of agriculture wastes as a substrate for biotechnologically interesting microorganisms is not only beneficial from the economical point of view, but is also important in view of the climate changes, and the necessity to find new resources for the growing human population. The search for a low-cost substrate that can be used for lipid (biofuel) production is also crucial in the face of limitation of fossils fuels. The first attempts to use xylose as a substrate for lipid production in Y. lipolytica have already been made [38,39].

\subsection{Composition of Y. lipolytica Dried Biomass}

Protein obtained from microbial biomass is referred to as "Single Cell Protein" (SCP). Environment-friendly production, reducing the pollution and which utilizes waste lignocellulosic materials, makes yeast biomass particularly attractive as a feed substitute. A mixture of citrus molasses and expired food was used to SCP production by S. cerevisiae [40]. $8.4 \mathrm{~g} / \mathrm{L}$ dry SCP could be produced by Candida intermedia from miscanthus straw [41]. Rice straw was also treated as bioresource for microbial protein production-Candida arborea reached 59.0\% crude protein content [42]. Likewise, Y. lipolytica was treated as a subject of research on SCP. Modified Y. lipolytica was tested for growth and production of SCP on waste cooking oil, sugarcane molasses, and crude glycerol [19]. However, the main goal of this research was to investigate the possibility to use the wild-type yeast strain cultivated on agroindustrial wastes as an SCP source. The total protein content in the dry biomass ranged from $30.5 \mathrm{~g} / 100 \mathrm{~g}$ to $45 \mathrm{~g} / 100 \mathrm{~g}$, in rye straw or in rye and oat brans, respectively. The reference of protein content for usage of biomass for nutritional application is a whole egg, which contains $48.1 \%$ 
protein. The employment of microbial biomass depends on the amino acids composition. The obtained profile of amino acids is shown in Table 3.

Table 3. Comparison of amino acid profile of $Y$. lipolytica biomass obtained on hydrolysates-based medium supplemented by YNB.

\begin{tabular}{cccccc}
\hline & & \multicolumn{3}{c}{ Yeast Biomass } & \multirow{2}{*}{ Whole Egg } \\
\cline { 3 - 5 } & & Rye Straw & Rye Bran & Oat Bran & \\
\hline Protein [g/100 g DM] & & $\mathbf{3 0 . 5} \pm \mathbf{0 . 2 6}$ & $\mathbf{4 4 . 5 3} \pm \mathbf{1 . 2 4}$ & $\mathbf{4 4 . 4 5} \pm \mathbf{0 . 6 5}$ & $\mathbf{4 8 . 1}$ \\
\hline & Arg & $1.27 \pm 0.02$ & $1.99 \pm 0.04$ & $2.06 \pm 0.01$ & 3.07 \\
& Phe & $1.38 \pm 0.06$ & $1.80 \pm 0.07$ & $1.79 \pm 0.02$ & 2.53 \\
& His & $0.85 \pm 0.05$ & $1.06 \pm 0.04$ & $1.10 \pm 0.01$ & 1.20 \\
& Ile & $1.39 \pm 0.04$ & $1.91 \pm 0.09$ & $1.91 \pm 0.02$ & 2.43 \\
Essential amino acid & Leu & $3.40 \pm 0.07$ & $3.38 \pm 0.10$ & $3.45 \pm 0.10$ & 4.15 \\
& Lys & $1.83 \pm 0.06$ & $2.93 \pm 0.16$ & $3.10 \pm 0.06$ & 3.34 \\
& MetS & $0.47 \pm 0.03$ & $0.87 \pm 0.07$ & $0.52 \pm 0.02$ & 1.50 \\
& Thr & $2.08 \pm 0.11$ & $2.31 \pm 0.10$ & $1.89 \pm 0.04$ & 2.13 \\
& Trp & nm & $0.35 \pm 0.03$ & $0.43 \pm 0.02$ & 0.78 \\
& EEA & 12.67 & 16.60 & 16.25 & 21.13 \\
& Val & $1.77 \pm 0.04$ & $2.36 \pm 0.10$ & $2.25 \pm 0.07$ & 2.99 \\
\hline & Ala & $1.78 \pm 0.04$ & $2.71 \pm 0.08$ & $2.75 \pm 0.04$ & 2.70 \\
& Cysh & $0.35 \pm 0.02$ & $0.59 \pm 0.05$ & $0.59 \pm 0.02$ & 1.07 \\
& Gly & $1.44 \pm 0.03$ & $2.18 \pm 0.10$ & $2.01 \pm 0.03$ & 1.62 \\
Dispensable amino acid & Asp & $3.18 \pm 0.06$ & $4.54 \pm 0.27$ & $4.29 \pm 0.08$ & 5.02 \\
& Glu & $4.02 \pm 0.17$ & $6.48 \pm 0.40$ & $5.37 \pm 0.04$ & 6.39 \\
& Pro & $1.30 \pm 0.07$ & $1.91 \pm 0.41$ & $1.57 \pm 0.07$ & 1.83 \\
& Ser & $1.56 \pm 0.05$ & $2.07 \pm 0.12$ & $2.02 \pm 0.04$ & 3.77 \\
& Tyr & $0.81 \pm 0.04$ & $1.50 \pm 0.02$ & $1.46 \pm 0.01$ & 1.44 \\
\hline
\end{tabular}

$\mathrm{nm}$-not measured; EAA—essential amino acids. Values are means \pm SD of three determinations.

Previously, it was shown that the Y. lipolytica A101 strain is able to produce up to $49 \%$ protein in dry biomass during fermentation on SK medium (a mix of vegetable oils, degumming and glycerol fractions formed during biofuel) [21]. In another study, Y. lipolytica strain S6 achieved 45\% protein in biomass obtained during fermentation on crude glycerol [20]. In this study, in the analyzed samples, the content of essential amino acids (EAA) was similar to the whole dried egg amino acids profile. The most similar values to reference results were obtained for oat bran-based medium. The only exception was the content of methionine since its content in the tested biomasses was significantly limited. However, these observations are in accordance with the previous reports that $Y$. lipolytica is poor in sulfur-containing amino acids [20]. The lowest EAA content was observed for rye straw-based media, because of the low level of protein in the dry biomass.

The biomass of yeast $Y$. lipolytica possesses a very good fatty acid profile; it includes many polyunsaturated fatty acids (PUFA) [43], which are essential in the balanced human diet. For this reason, the fatty acid profile of lipids in the obtained biomasses was analyzed (Table 4). It was found that metabolic engineering of $Y$. lipolytica allows for considerable increase of fatty acid production and accumulation $[38,44,45]$. However, the wild-type yeast strain, which has been granted GRAS status, might be easily introduced as a microbial product into food and feed industries. 
Table 4. Fatty acid composition (percent of Total Cellular Lipids; TCL) of Y. lipolytica biomass obtained on hydrolysates-based medium supplemented by YNB.

\begin{tabular}{cccccc}
\hline & & \multicolumn{3}{c}{ Yeast Biomass } & \multirow{2}{*}{ Whole Egg } \\
\cline { 2 - 4 } & & Rye Straw & Rye Bran & Oat Bran & \\
\hline & Lipids [g/100 g DM] & $\mathbf{8 . 2 8}$ & $\mathbf{1 1 . 2 2}$ & $\mathbf{1 1 . 1 3}$ & $\mathbf{4 0 . 1 0}$ \\
\hline \multirow{2}{*}{ Saturated [\%TCL] } & $14: 0$ & 0.0 & 0.0 & $2.41 \pm 1.74$ & 0.34 \\
& $15: 0$ & $2.65 \pm 0.51$ & $2.31 \pm 0.24$ & $2.39 \pm 0.31$ & 0.0 \\
& $16: 0$ & $11.61 \pm 1.44$ & $8.58 \pm 0.57$ & $8.68 \pm 0.69$ & 26.95 \\
& $18: 0$ & $5.84 \pm 0.04$ & $6.13 \pm 0.62$ & $6.35 \pm 0.76$ & 9.90 \\
& $24: 0$ & $14.85 \pm 1.91$ & $2.81 \pm 0.05$ & $9.26 \pm 1.23$ & 0.0 \\
& $\Sigma$ & 34.95 & 19.83 & 29.09 & 37.19 \\
\hline Unsaturated [\% TCL] & $16: 1$ & $2.56 \pm 0.04$ & $3.29 \pm 0.20$ & $3.53 \pm 0.21$ & 2.09 \\
& $17: 1$ & $1.38 \pm 0.54$ & $3.56 \pm 0.19$ & $3.38 \pm 0.25$ & 0.00 \\
& $18: 1$ & $37.74 \pm 2.82$ & $59.28 \pm 4.09$ & $50.82 \pm 4.25$ & 39.20 \\
& $18: 2$ & $19.52 \pm 2.20$ & $12.81 \pm 0.66$ & $11.91 \pm 0.16$ & 17.58 \\
& $18: 3$ & 0.0 & 0.0 & 0.0 & 0.62 \\
& $20: 1$ & 0.0 & 0.0 & 0.0 & 0.25 \\
& $20: 4$ & 0.0 & 0.0 & 0.0 & 1.77 \\
& $22: 1$ & $3.86 \pm 0.91$ & 0.0 & 0.0 & 0.0 \\
& $22: 6$ & 0.0 & 0.0 & 0.0 & 0.50 \\
& $\Sigma$ & 65.06 & 78.94 & 69.64 & 62.01 \\
\hline
\end{tabular}

Values are means \pm SD of three determinations.

Despite the fact that the content of lipids in biomass was at a lower level than in whole egg, the fatty acid profile was significantly enriched in unsaturated fatty acids (UFA) content. In addition, also in the saturated fatty acid pool, differences were observed. In all tested biomasses, the presence of pentadecanoic acid, which is absent in egg, was noted. Moreover, the palmitic acid content was reduced. Interestingly, a long-chain lignoceric acid was detected in the yeast biomass, and the highest level was observed for rye straw-based medium. The highest concentration of UFA was achieved in the medium with rye bran hydrolysate. The content of both isomers of C18:2 (linoleic acid and linolelaidic acid) ranged from 11.91 to 19.52 in the total lipid pool for oat bran and rye straw hydrolysate, respectively. Oleic acid was the most abundant fatty acid in the total cellular lipid pool, which confirms the previous reports-Y. lipolytica biomass produced with media containing $25 \mathrm{~g} / \mathrm{L}$ of raw glycerol consisted of more than $50 \%$ of this acid [20]. Different $Y$. lipolytica strains isolated from soil and cheese reached values between $35.5 \%$ and $53.5 \%$ oleic acid content in the biomass [24]. For the rye and oat bran-based media, oleic acid achieved $59.28 \%$ and $50.82 \%$ TCL, respectively, which is significantly higher than in whole egg.

\section{Conclusions}

The vast amounts of agricultural wastes impose an obligation on modern society to follow the sustainable development approach. One of the key elements is development of biotechnology processes for enabling reuse of waste. The present study shows that lignocellulosic materials such as rye straw, rye bran and oat bran can be hydrolyzed to release carbon sources for growing feed-related yeast biomass. The achieved level of biomass growth does not differ significantly from the value of production in other similar processes using other waste materials. In future research, the production scale should be increased by using fed-batch bioreactor processes or combined with use of a cheaper, potentially also waste, nitrogen source. In conclusion, Y. lipolytica A101 is a future-oriented microorganism for producing microbial feed-related biomass from lignocellulosic agricultural waste. Rye bran and oat bran were found to be efficient base media for cultivating Y. lipolytica. 
Author Contributions: Conceptualization, K.D. and A.D.; methodology, K.D., W.P. and A.D.; validation, K.D.; formal analysis, K.D.; investigation, K.D.; resources, W.P. and A.D.; data curation, K.D.; writing-original draft preparation, K.D.; writing - review and editing, A.M.M. and A.D.; visualization, K.D.; supervision, A.M.M. and A.D.; project administration, A.D.; funding acquisition, A.D. All authors have read and agreed to the published version of the manuscript.

Funding: This work was financially supported by the National Science Center, Poland, project UMO-2017/26/E/NZ9/00975. The publication fee is co-financed under the Leading Research Groups support project from the subsidy increased for the period 2020-2025 in the amount of $2 \%$ of the subsidy referred to Art. 387 (3) of the Law of 20 July 2018 on Higher Education and Science, obtained in 2019.

Conflicts of Interest: The authors declare no conflict of interest.

\section{References}

1. Schmoll, M. Regulation of plant cell wall degradation by light in Trichoderma. Fungal Biol. Biotechnol. 2018, 5, 10. [CrossRef] [PubMed]

2. Rosales-Calderon, O.; Arantes, V. A review on commercial-scale high-value products that can be produced alongside cellulosic ethanol. Biotechnol. Biofuels 2019, 12, 240. [CrossRef] [PubMed]

3. Yu, X.; Zheng, Y.; Dorgan, K.M.; Chen, S. Oil production by oleaginous yeasts using the hydrolysate from pretreatment of wheat straw with dilute sulfuric acid. Bioresour. Technol. 2011, 102, 6134-6140. [CrossRef]

4. Marriott, P.E.; Gomez, L.D.; McQueen-Mason, S.J. Unlocking the potential of lignocellulosic biomass through plant science. New Phytol. 2016, 209, 1366-1381. [CrossRef]

5. Girio, F.M.; Fonseca, C.; Carvalheiro, F.; Duarte, L.C.; Marques, S.; Bogel-Lukasik, R. Hemicelluloses for fuel ethanol: A review. Bioresour. Technol. 2010, 101, 4775-4800. [CrossRef]

6. Brandenburg, J.; Poppele, I.; Blomqvist, J.; Puke, M.; Pickova, J.; Sandgren, M.; Rapoport, A.; Vedernikovs, N.; Passoth, V. Bioethanol and lipid production from the enzymatic hydrolysate of wheat straw after furfural extraction. Appl. Microbiol. Biotechnol. 2018, 102, 6269-6277. [CrossRef]

7. Fei, Q.; O'Brien, M.; Nelson, R.; Chen, X.; Lowell, A.; Dowe, N. Enhanced lipid production by Rhodosporidium toruloides using different fed-batch feeding strategies with lignocellulosic hydrolysate as the sole carbon source. Biotechnol. Biofuels 2016, 9, 130. [CrossRef]

8. Mardetko, N.; Galić, M.; Santek, B.; Trontel, A.; Grubišić, M.; Novak, M. Bioethanol production from dilute-acid pre-treated wheat straw liquor hydrolysate by genetically engineered Saccharomyces cerevisiae. Chem. Biochem. Eng. Q. 2019, 32, 483-499. [CrossRef]

9. Flores-Gomez, C.A.; Escamilla Silva, E.M.; Zhong, C.; Dale, B.E.; da Costa Sousa, L.; Balan, V. Conversion of lignocellulosic agave residues into liquid biofuels using an AFEX-based biorefinery. Biotechnol. Biofuels 2018, 11, 7. [CrossRef]

10. Tsigie, Y.A.; Wang, C.Y.; Kasim, N.S.; Diem, Q.D.; Huynh, L.H.; Ho, Q.P.; Truong, C.T.; Ju, Y.H. Oil production from Yarrowia lipolytica Po1g using rice bran hydrolysate. J. Biomed. Biotechnol. 2012, 2012, 378384. [CrossRef]

11. Tsigie, Y.A.; Wang, C.Y.; Truong, C.T.; Ju, Y.H. Lipid production from Yarrowia lipolytica Po1g grown in sugarcane bagasse hydrolysate. Bioresour. Technol. 2011, 102, 9216-9222. [CrossRef] [PubMed]

12. Papanikolaou, S.; Chevalot, I.; Komaitis, M.; Marc, I.; Aggelis, G. Single cell oil production by Yarrowia lipolytica growing on an industrial derivative of animal fat in batch cultures. Appl. Microbiol. Biotechnol. 2002, 58, 308-312. [CrossRef] [PubMed]

13. Papanikolaou, S.; Muniglia, L.; Chevalot, I.; Aggelis, G.; Marc, I. Accumulation of a cocoa-butter-like lipid by Yarrowia lipolytica cultivated on agro-industrial residues. Curr. Microbiol. 2003, 46, 124-130. [CrossRef] [PubMed]

14. Cybulski, K.; Tomaszewska-Hetman, L.; Rakicka, M.; Juszczyk, P.; Rywinska, A. Production of pyruvic acid from glycerol by Yarrowia lipolytica. Folia Microbiol. 2019, 64, 809-820. [CrossRef] [PubMed]

15. Rakicka, M.; Wolniak, J.; Lazar, Z.; Rymowicz, W. Production of high titer of citric acid from inulin. BMC Biotechnol. 2019, 19, 11. [CrossRef]

16. Rakicka, M.; Biegalska, A.; Rymowicz, W.; Dobrowolski, A.; Mironczuk, A.M. Polyol production from waste materials by genetically modified Yarrowia lipolytica. Bioresour. Technol. 2017, 243, 393-399. [CrossRef]

17. Dobrowolski, A.; Drzymala, K.; Rzechonek, D.A.; Mitula, P.; Mironczuk, A.M. Lipid production from waste materials in seawater-based medium by the yeast Yarrowia lipolytica. Front. Microbiol. 2019, 10, 547. [CrossRef] 
18. Dourou, M.; Aggeli, D.; Papanikolaou, S.; Aggelis, G. Critical steps in carbon metabolism affecting lipid accumulation and their regulation in oleaginous microorganisms. Appl. Microbiol. Biotechnol. 2018, 102, 2509-2523. [CrossRef]

19. Yan, J.; Han, B.; Gui, X.; Wang, G.; Xu, L.; Yan, Y.; Madzak, C.; Pan, D.; Wang, Y.; Zha, G.; et al. Engineering Yarrowia lipolytica to simultaneously produce lipase and single cell protein from agro-industrial wastes for feed. Sci. Rep. 2018, 8, 758. [CrossRef]

20. Juszczyk, P.; Rymowicz, W.; Kita, A.; Rywińska, A. Biomass production by Yarrowia lipolytica yeast using waste derived from the production of ethyl esters of polyunsaturated fatty acids of flaxseed oil. Ind. Crop. Prod. 2019, 138, 111590. [CrossRef]

21. Jach, M.E.; Sajnaga, E.; Świder, R.; Baier, A.; Mickowska, B.; Juda, M.; Chudzik-Rząd, B.; Szyszka, R.; Malm, A. Yarrowia lipolytica grown on biofuel waste as a source of single cell protein and essential amino acids for human diet. Saudi J. Med. Pharm. Sci. 2017, 3, 1344-1351.

22. Mironczuk, A.M.; Rakicka, M.; Biegalska, A.; Rymowicz, W.; Dobrowolski, A. A two-stage fermentation process of erythritol production by yeast Y. lipolytica from molasses and glycerol. Bioresour. Technol. 2015, 198, 445-455. [CrossRef] [PubMed]

23. Cherdthong, A.; Sumadong, P.; Foiklang, S.; Milintawisamai, N.; Wanapat, M.; Chanjula, P.; Gunun, N.; Gunun, P. Effect of post-fermentative yeast biomass as a substitute for soybean meal on feed utilization and rumen ecology in Thai native beef cattle. J. Anim. Feed Sci. 2019, 28, 238-243. [CrossRef]

24. Juszczyk, P.; Tomaszewska, L.; Kita, A.; Rymowicz, W. Biomass production by novel strains of Yarrowia lipolytica using raw glycerol, derived from biodiesel production. Bioresour. Technol. 2013, 137, 124-131. [CrossRef] [PubMed]

25. Overland, M.; Skrede, A. Yeast derived from lignocellulosic biomass as a sustainable feed resource for use in aquaculture. J. Sci. Food Agric. 2017, 97, 733-742. [CrossRef]

26. Huyben, D.; Boqvist, S.; Passoth, V.; Renstrom, L.; Allard Bengtsson, U.; Andreoletti, O.; Kiessling, A.; Lundh, T.; Vagsholm, I. Screening of intact yeasts and cell extracts to reduce Scrapie prions during biotransformation of food waste. Acta Vet. Scand. 2018, 60, 9. [CrossRef]

27. Wojtatowicz, M.; Rymowicz, W.; Kautola, H. Comparison of different strains of the yeast Yarrowia lipolytica for citric acid production from glucose hydrol. Appl. Biochem. Biotechnol. 1991, 31, 165-174. [CrossRef]

28. Devillers, H.; Brunel, F.; Polomska, X.; Sarilar, V.; Lazar, Z.; Robak, M.; Neuveglise, C. Draft genome sequence of Yarrowia lipolytica strain A-101 isolated from polluted soil in Poland. Genome Announc. 2016, 4, e01094-16. [CrossRef]

29. Browse, J.; McCourt, P.J.; Somerville, C.R. Fatty acid composition of leaf lipids determined after combined digestion and fatty acid methyl ester formation from fresh tissue. Anal. Biochem. 1986, 152, 141-145. [CrossRef]

30. Kucharska, K.; Rybarczyk, P.; Holowacz, I.; Lukajtis, R.; Glinka, M.; Kaminski, M. Pretreatment of lignocellulosic materials as substrates for fermentation processes. Molecules 2018, 23, 2937. [CrossRef]

31. Pauly, M.; Keegstra, K. Cell-wall carbohydrates and their modification as a resource for biofuels. Plant J. 2008, 54, 559-568. [CrossRef] [PubMed]

32. Ryu, S.; Trinh, C.T. Understanding functional roles of native pentose-specific transporters for activating dormant pentose metabolism in Yarrowia lipolytica. Appl. Environ. Microbiol. 2018, 84. [CrossRef] [PubMed]

33. Rodriguez, G.M.; Hussain, M.S.; Gambill, L.; Gao, D.; Yaguchi, A.; Blenner, M. Engineering xylose utilization in Yarrowia lipolytica by understanding its cryptic xylose pathway. Biotechnol. Biofuels 2016, 9, 149. [CrossRef] [PubMed]

34. Xiao, B.; Sun, X.F.; Sun, R.C. Chemical, structural, andthermalcharacterizations of alkali-soluble lignins and hemicelluloses, and cellulosefrom maize stems, rye straw, and rice straw. Polym. Degrad. Stab. 2001, 74, 307-319. [CrossRef]

35. Zhao, C.; Gu, D.; Nambou, K.; Wei, L.; Chen, J.; Imanaka, T.; Hua, Q. Metabolome analysis and pathway abundance profiling of Yarrowia lipolytica cultivated on different carbon sources. J. Biotechnol. 2015, 206, 42-51. [CrossRef]

36. Mironczuk, A.M.; Kosiorowska, K.E.; Biegalska, A.; Rakicka-Pustulka, M.; Szczepanczyk, M.; Dobrowolski, A. Heterologous overexpression of bacterial hemoglobin $\mathrm{VHb}$ improves erythritol biosynthesis by yeast Yarrowia lipolytica. Microb. Cell Fact. 2019, 18, 176. [CrossRef] 
37. Zhu, L.Y.; Zong, M.H.; Wu, H. Efficient lipid production with Trichosporon fermentans and its use for biodiesel preparation. Bioresour. Technol. 2008, 99, 7881-7885. [CrossRef]

38. Ledesma-Amaro, R.; Lazar, Z.; Rakicka, M.; Guo, Z.; Fouchard, F.; Coq, A.C.; Nicaud, J.M. Metabolic engineering of Yarrowia lipolytica to produce chemicals and fuels from xylose. Metab. Eng. 2016, 38, 115-124. [CrossRef]

39. Li, H.; Alper, H.S. Enabling xylose utilization in Yarrowia lipolytica for lipid production. Biotechnol. J. 2016, 11, 1230-1240. [CrossRef]

40. Gervasi, T.; Pellizzeri, V.; Calabrese, G.; Di Bella, G.; Cicero, N.; Dugo, G. Production of single cell protein (SCP) from food and agricultural waste by using Saccharomyces cerevisiae. Nat. Prod. Res. 2018, 32, 648-653. [CrossRef]

41. Wu, J.; Hu, J.; Zhao, S.; He, M.; Hu, G.; Ge, X.; Peng, N. Single-cell protein and xylitol production by a novel yeast strain Candida intermedia FL023 from lignocellulosic hydrolysates and xylose. Appl. Biochem. Biotechnol. 2018, 185, 163-178. [CrossRef] [PubMed]

42. Zheng, Y.G.; Chen, X.L.; Wang, Z. Microbial biomass production from rice straw hydrolysate in airlift bioreactors. J. Biotechnol. 2005, 118, 413-420. [CrossRef] [PubMed]

43. Bellou, S.; Triantaphyllidou, I.E.; Aggeli, D.; Elazzazy, A.M.; Baeshen, M.N.; Aggelis, G. Microbial oils as food additives: Recent approaches for improving microbial oil production and its polyunsaturated fatty acid content. Curr. Opin. Biotechnol. 2016, 37, 24-35. [CrossRef] [PubMed]

44. Dobrowolski, A.; Drzymala, K.; Mitula, P.; Mironczuk, A.M. Production of tailor-made fatty acids from crude glycerol at low $\mathrm{pH}$ by Yarrowia lipolytica. Bioresour. Technol. 2020, 314, 123746. [CrossRef]

45. Yook, S.D.; Kim, J.; Gong, G.; Ko, J.K.; Um, Y.; Han, S.O.; Lee, S.-M. High-yield lipid production from lignocellulosic biomass using engineered xylose-utilizing Yarrowia lipolytica. GCB Bioenergy 2020, 12, 670-679. [CrossRef]

(C) 2020 by the authors. Licensee MDPI, Basel, Switzerland. This article is an open access article distributed under the terms and conditions of the Creative Commons Attribution (CC BY) license (http://creativecommons.org/licenses/by/4.0/). 